\title{
Diagnostic and Curative Approach for Hydatid Cyst of Thigh
}

\author{
Mohamed Abdulla Alkatta ${ }^{1^{*}}$, Wail Mohammed Alqatta ${ }^{2}$ \\ ${ }^{1}$ Department of General Surgery, Faculty of Medicine and Medical Science, Sana'a University, Sana'a, Yemen \\ ${ }^{2}$ Department of General Surgery, Münster University, Münster, Germany \\ Email: ^drkatta2002@yahoo.com
}

How to cite this paper: Alkatta, M.A. and Alqatta, W.M. (2019) Diagnostic and Curative Approach for Hydatid Cyst of Thigh. Open Access Library Journal, 6: e5858.

https://doi.org/10.4236/oalib.1105858

Received: October 15, 2019

Accepted: November 8, 2019

Published: November 11, 2019

Copyright (๑) 2019 by author(s) and Open Access Library Inc.

This work is licensed under the Creative Commons Attribution International License (CC BY 4.0).

http://creativecommons.org/licenses/by/4.0/

\begin{abstract}
Introduction: Hydatid disease is a parasitic disease caused by Echinococcus species, and is a serious sometimes fatal, that is endemic in many parts of the world, especially in South America, the Middle East including Yemen, Australia, and the mediteranean region. Hydatid disease of the skeletal muscle is rare. Presentation of Case: This article presents an unusual three Yemeni cases of subcutaneous and intramuscular hydatid cyst of the thigh. The ages of one male and two women are 32, 38 and 27 years respectively. They admit to IBN Sina hospital complain of dull aching pain, but no fever or other symptoms indicating infection or metastatic neoplastic soft tissue mass, lipoma or cystic swelling for differential diagnosis. Clinical manifestation was nonspecific and the diagnosis mainly depends on radiological evaluation which included mainly CT, MRI and laboratory investigation which is mainly ELISA test for Echinococcus granulosus Ab. After the patient admitted to the hospital, preoperative albenazole for ten days to treat patient, and surgical excision procedure pericystectomy were performed for the cyst combined with postoperative albendazole. In our 3 cases, this surgical approach was performed to extract the hydatic cyst completely intact without rupture and was achieved in 2 cases, while rupture occur in one case (case No. 3). The cyst was ruptured during intramuscular dissection. In spite of that, she passed well without intra or post-operative early or late complications. Use of intra-operative hypertonic $10 \%$ saline solution is mandatory to prevent the dissemination of protoscoleces. Chemotherapy enabled the authors to treat the patient with preoperative albenazole for ten days and to prevent postoperative recurrence of the disease. Discussion: The diagnosis of echinococcosis should be considered when soft tissue mass grows slowly for months or years, in any patient from the endemic area. Patients presented with this rare hydatic cyst diseses in subcutaneous and intramuscular space of the thigh,
\end{abstract}


whom were found in our country (Yemen) were successfully treated with pericystectomy. Preoperative intake of albenazole is very important to minimize intra-cystic pressure, increase the incidence of intra-operative rupture of the cyst during manipulation and to prevent post operative parasitic dissemination. Conclusion: Surgical pericystectomy combined with albendazole is known to be curative for soft tissue hydatic cyst. Rare cases like this must be truly diagnosis and treated to prevent severe complication of this disease.

\section{Subject Areas}

Surgery \& Surgical Specialties

\section{Keywords}

Pericystecyomy Intramuscular, Hydatidcyst, Thigh, Surgery Echinococcosis

\section{Introduction}

Hydatid disease is an anthropozoonosis caused by Echinococcus species mainly include granulosus, multilocularis and oligarthrus, with granulosus commonly responsible for cysts in predators such as wolves, dogs, and foxes as well as intermediate hosts such as cattle, sheep and goats [1]. Humans are a coincidental intermediate host. The disease is more frequent in the Middle East where Yemen was one country of them, Central Europe, Australia, South America and Mediterranean basin and occurs worldwide including tropical and subtropical regions [2], where cattle breeding is very plenty. Larvae of this parasite can develop in any part of the human body with the liver $(68.8 \%-80 \%)$ and lungs $(10 \%-$ $22.4 \%)$, representing as the most frequent localizations. Other localizations rarely reported in literature include the skeleton, spleen, peritoneum, kidney, brain, cardiac muscle and even subcutis. Primary muscular hydatidosis is uncommon even in endemic regions (1\% to 4\%) [3]. This case report has been presented according to SCARE guideline [4].

\section{Three Case Reports}

\section{Case 1:}

A 32 years old male patient presented to IBN SINA Hospital Sana'a-Yemen complaining of swelling at the left thigh since 7 months of gradual onset and progressive course associated with mild dull aching pain but no fever or other symptoms indicating infection or metastatic neoplastic soft tissue mass. Clinical evaluation showed discrete subcutaneouss swelling at the anterolateral aspect of left thigh, about $12 \times 10 \mathrm{~cm}$ in size, firm in consistency, slightly tender, not fluctuant and of ill-defined edge (See Figure 1). Lipoma or cystic swelling for differential diagnosis was the main provisional diagnosis. Computed tomography and ELISA test for Echinococcus granulosus Ab confirmed the diagnosis of primary hydatid cyst of thigh. Preoperative albendazole $15 \mathrm{mg} / \mathrm{kg}$ was given for 10 


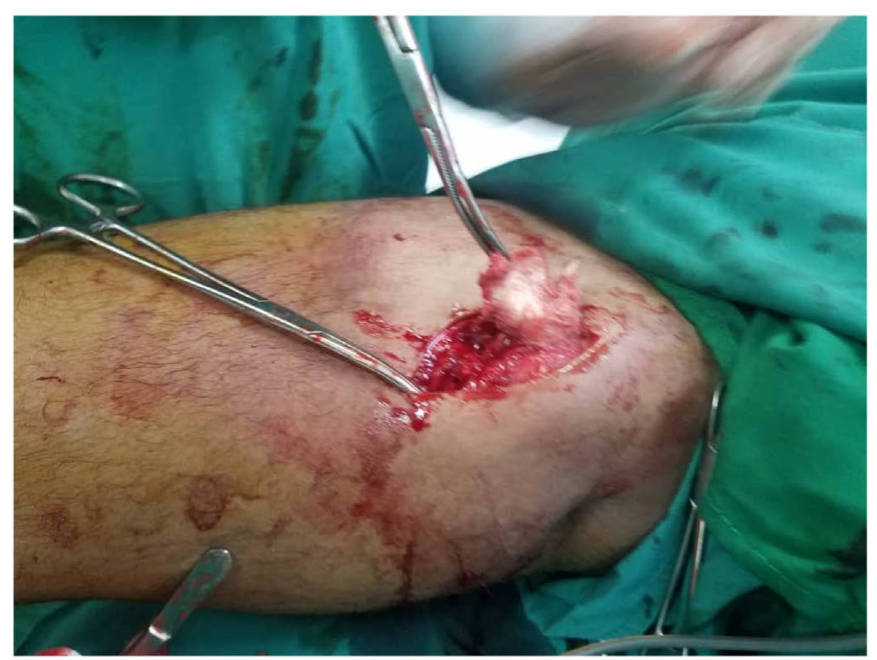

Figure 1. Hydatic cyst in the third of lateral aspect of left thigh of male.

days after which the patient admitted to the hospital and surgical procedure in the form of pericystectomy was performed for the cyst laying subcutaneously at the upper third of the anterolateral aspect of left thigh The wound is closed 2 layers after irrigation with $10 \%$ hypertonic saline. Postoperative albendazole 15 $\mathrm{mg} / \mathrm{kg}$ for three cycles each one is weeks with one-week interval in between for assessment of liver function test. The patient passed well since 3 years and 4 months with no recurrence or reappearance of hydatid cyst anywhere .

Case 2:

A 35 years old female patient coming from rural region presented with swelling of right thigh discovered by the patient, acute onset, stationary course since 7 years, was presented to hospital with swelling in the middle third of anterior aspect of right thigh since 7 years. The main complaint of the patient was nonspecific dull aching pain at the same site mention above, gradual in onset, stationary course and associated with no fever or other systemic or right leg symptoms. There was no history of liver or pulmonary hydatid cysts, which are the main site of the disease. Clinical evaluation of right thigh showed just fullness at the same site of complaint without clear manifestation of discrete swelling. Immunological Serologic (ELISA) test was positive, and CT (See Figure 2) was typical for Hydatic cyst, right upper thigh shows about $10 \times 5 \times 3 \mathrm{~cm}$ elongated shape, well defined large cystic lesion contain internal tiny cyst like daughter cyst located at upper anterior lateral aspect, within the lateral muscle compartment vastus intermedias shows no contrast enhancement rising image of intra muscle Hydatic cyst no calcification.

Preoperative adjuvant chemotherapy in form of albendazole $15 \mathrm{mg} / \mathrm{kg}$ was given as usual for 10 days after which pericystectomy was performed. Post-operative albendazole was given for 3 months, and was passed well without recurrence. Pericystectomy of Hydatid cyst of right thigh: Through longtadial incision at junction of upper and middle third of anteriolateral aspect of right thigh pericystectomy (complete excision of right hydatid cyst measuring about $2 \times 10 \mathrm{~cm}$ ) 
situated inside the muscle fibers of lateral vastus muscles of thigh see (Figure 3 and Figure 4). Dissection the cyst, followed by aspiration of its fluid content injection of $10 \%$ hyper tonic saline started (See Figure 5), followed by complete pericystectomy. The wound was closed in three layers with intramuscular suction drain. Excised of cyst contain multiple daughter small cysts (See Figure 6 and Figure 7).

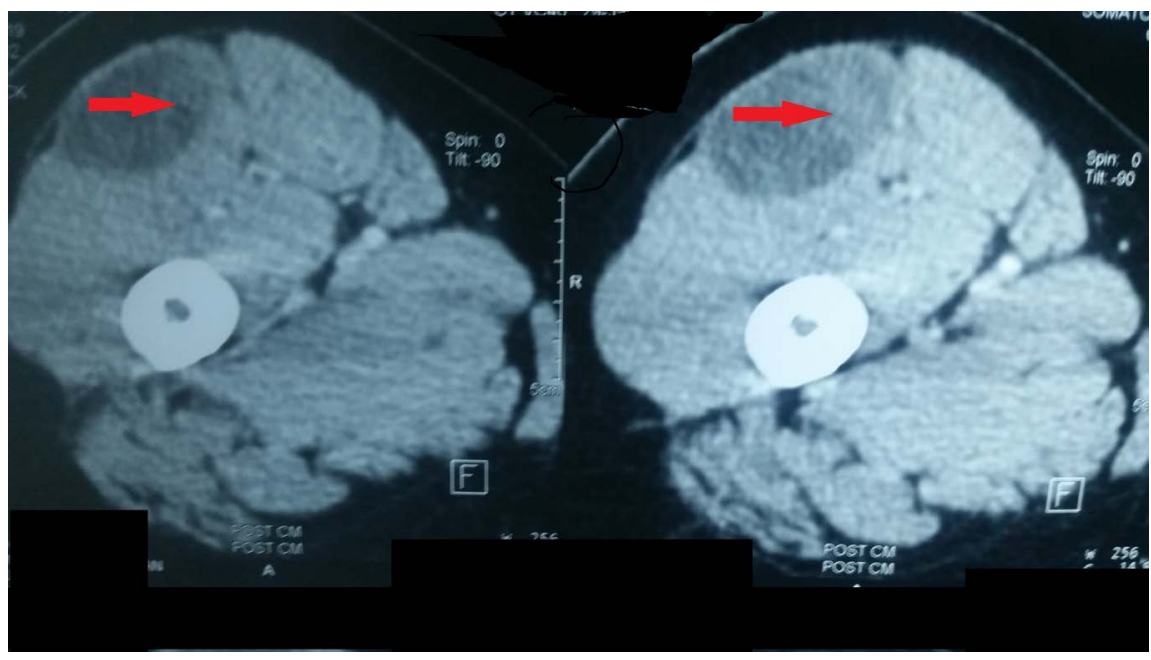

Figure 2. CT was showing, right upper thigh red arrow shows about $10 \times 5 \times 3 \mathrm{~cm}$ elongated shape well defined large cystic lesion contain internal tiny cyst like daughter cyst located at upper anterior lateral aspect within the lateral muscle compartment vastus intermedias shows no contrast enhancement rising image of intra muscle Hydatic cyst no calcification.

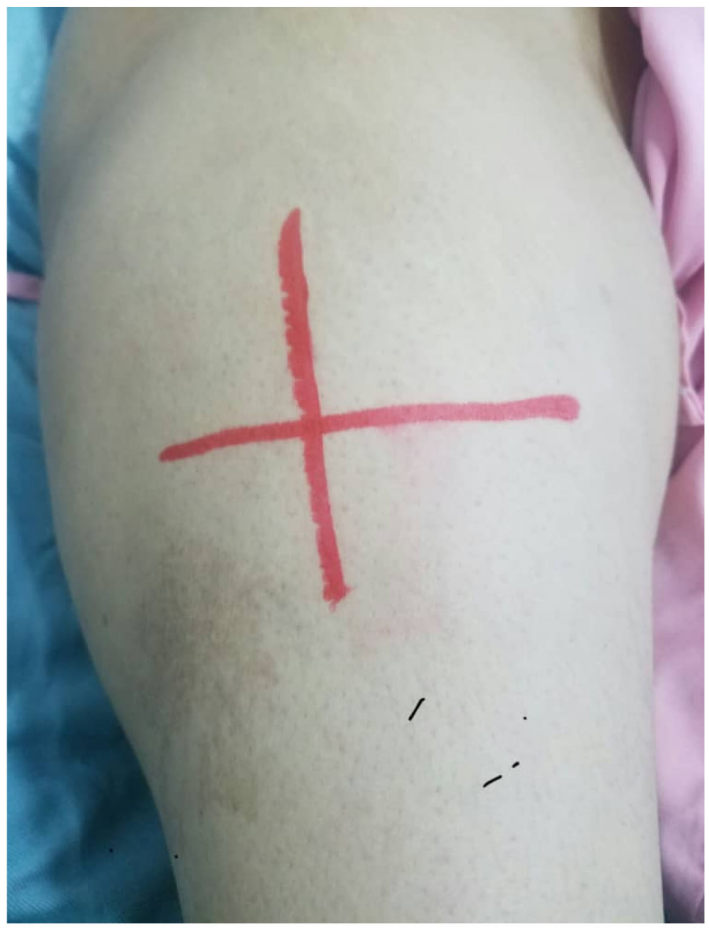

Figure 3. Hydatic cyst of anteriorlaterial aspect of right thigh of female. 


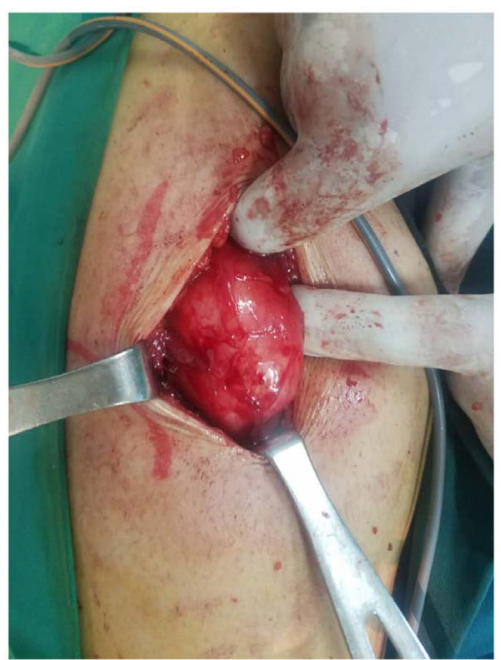

Figure 4. Pericystectomy of the cyst laying inside vatus lintermedius muscle.

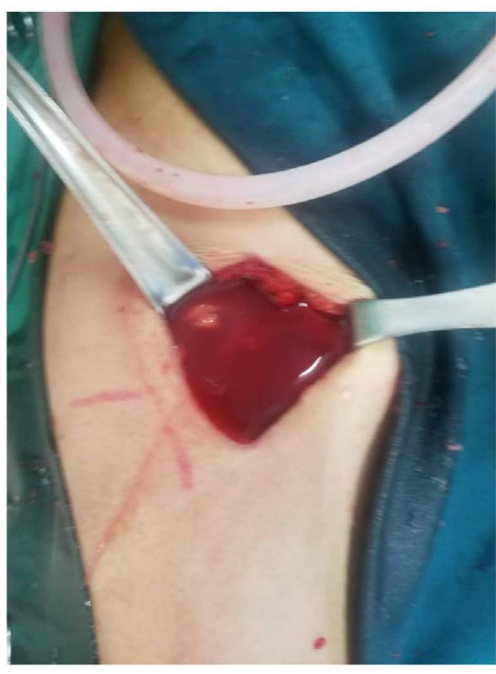

Figure 5. Irrigation of the wound with hypertonic saline.

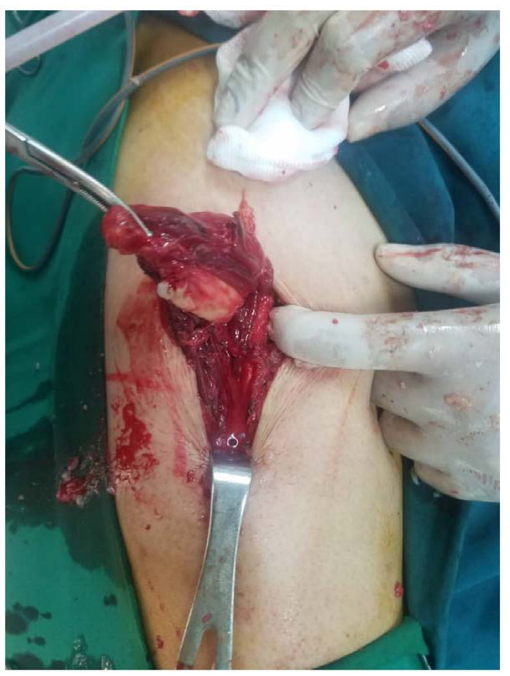

Figure 6. Excised cyst of intramuscular right thigh contain multiple daughter small cyst. 


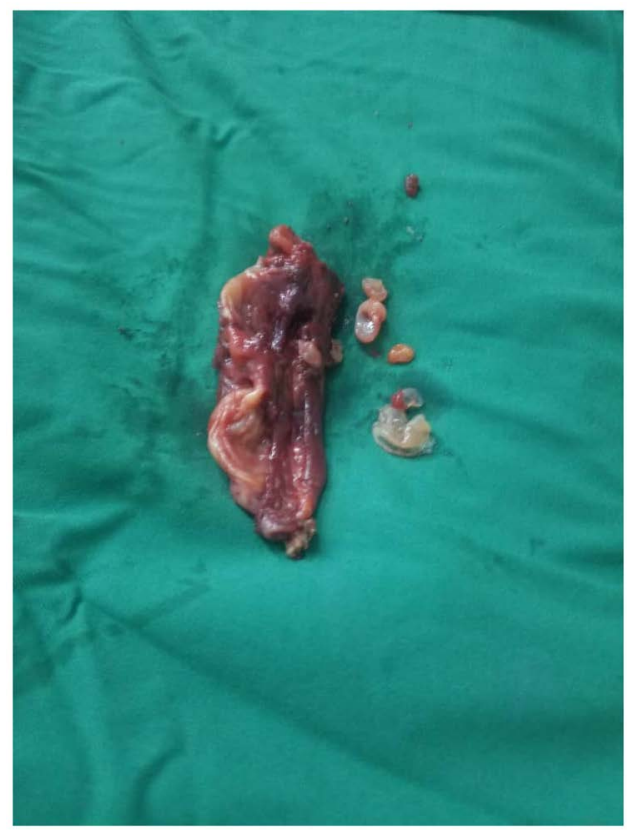

Figure 7. Cyst of intramuscular right thigh and contain multiple daughter small cyst.

\section{Case 3:}

A 27 years old female patient presented to IBN Sina coming from rural region presented with swelling of left thigh since 14 months which discovered by the patient, after recurrent attacks of dull aching pain especially during walking and extension of the left knee joint. Clinically the swelling, which was not tender, firm in consistency and of ill-defined edge, occupied the middle third of left thigh posteriorly. Serological (ELISA) test was Negative but MRI (Figure 8) as show in Left middle thigh, red arrow shows about $15 \times 13 \mathrm{~cm}$ well defined large Hydatic cystic lesion located superficially. The cyst was typical lying on the superficial layer of vastus lateralis muscle and posterior aspect of vastus lateralis muscle. Preoperative adjuvant chemotherapy in form of albendazole $15 \mathrm{mg} / \mathrm{kg}$ was given as usual for 10 days after which pericystectomy was performed. Hydatic cyst of left thigh during dissection the cyst was in tensed ,rupture have been occurred (see Figure 9, Figure 10), and the content of the cyst also disseminated in the wound cavity, rapid sucking of the laminated membrane, daughter cyst and irrigated with $10 \%$ hyper tonic saline was performed. The wound was closed with subcutaneous tissue and skin in 3 layers with suction drain inside. Postoperative albendazole in the same dose was recommended for 3 cycles each one is 3 weeks with one-week interval in between for assessment of LFT before starting the next one, as usual the patient passed well without recurrence since 2.7 years.

\section{Discussion}

Primary hydatid disease of the skeletal muscle is rare, as the parasite has to cross hepatic and pulmonary barriers to reach the muscles [5]. The high lactic acid 


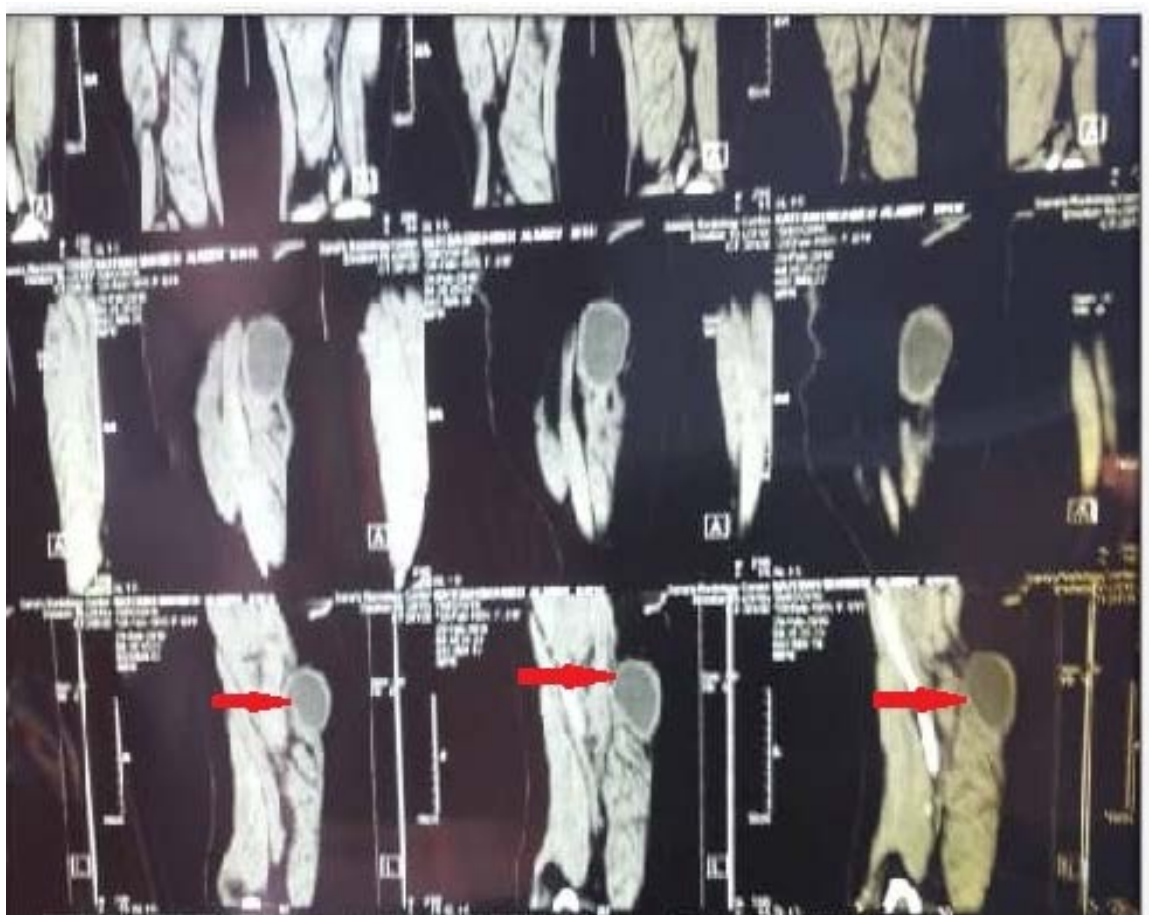

Figure 8. MRI was showing left middle thigh about $15 \times 13 \mathrm{~cm}$ well defined large Hydatic cystic lesion located at superficial layer, and posterior aspect of cyst resting on superficial muscle layer.

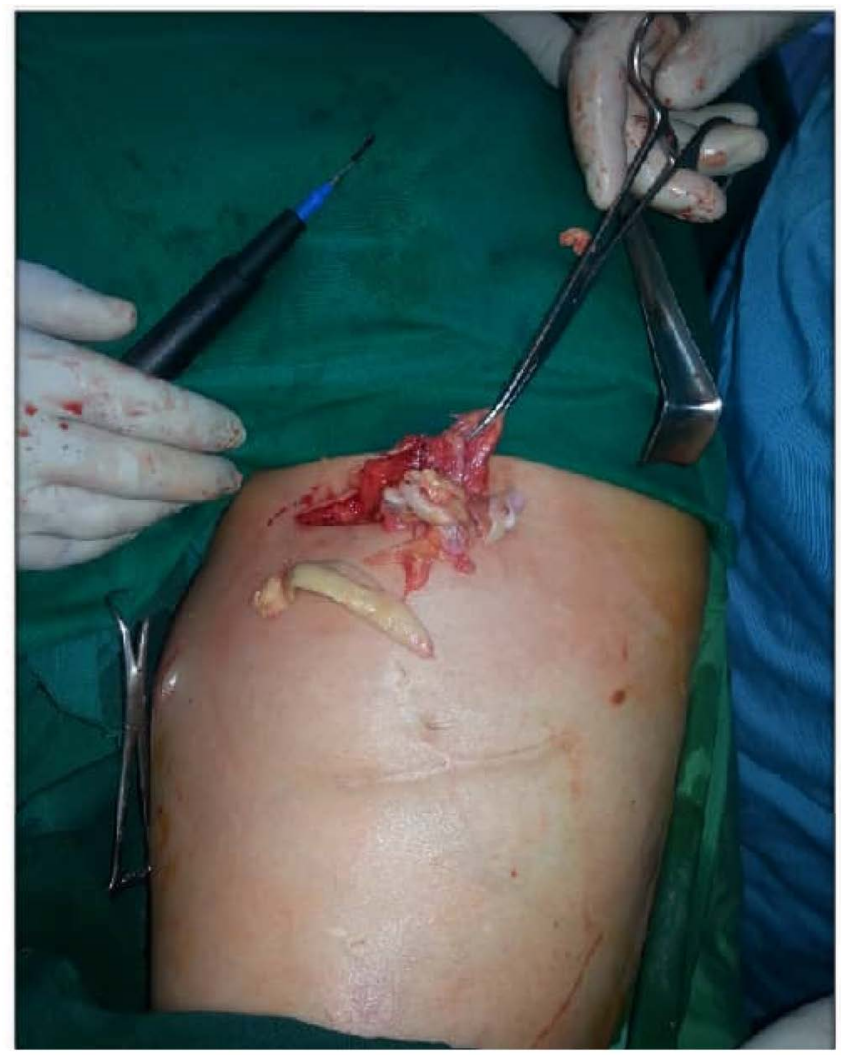

Figure 9. Excised cyst of intramuscular left thigh and contain multiple daughter small cysts. 


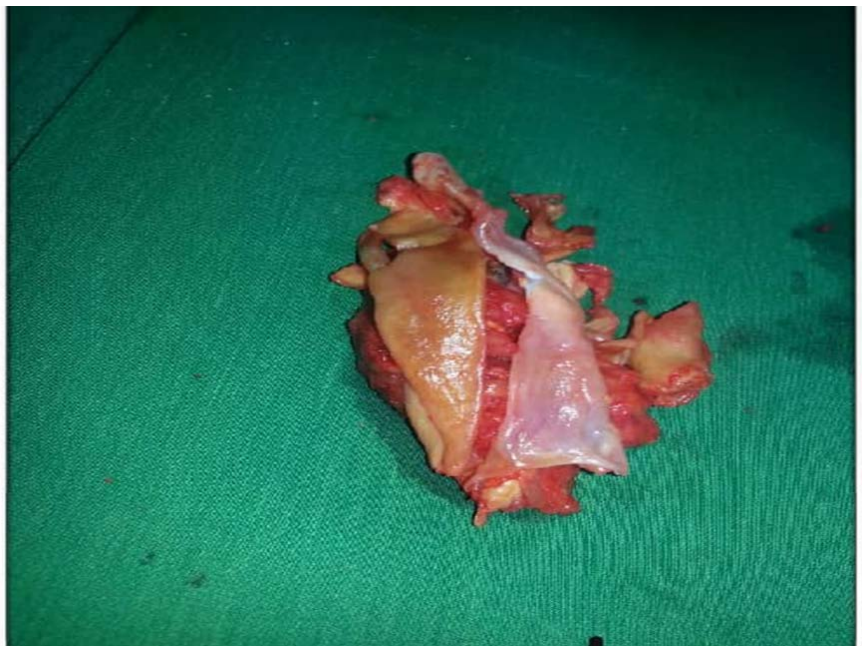

Figure 10. Multiple daughter small cysts.

level in muscle tissue considered unfavorable for the survival of parasite [6]. The above-mentioned three case patients had not been operated for hydatid disease previously and thoracic-abdominal radiological investigations did not reveal any hydatid cyst there. So, these patients were diagnosed as having primary hydatid disease of thigh.

Provisional diagnosis of echinococcosis should be considered when slowly growing soft tissue mass is present since several months in any patient from endemic area, Yemen considered as an endemic area and there are some cases found in Saudi Arabia Diagnosis as a thigh hydatic cyst, where patient was coming from Yemen [2].

Serologic tests and ultrasonography should be performed before any surgical procedure. Hydatid serology is only valuable when it is positive, negative serology does not exclude hydatic disease [4]. Serologic test (ELISA) was positive in female case.

Muscular Hydatic cyst is an insidious infection with no specific symptoms. Possible differential diagnoses include lipoma, calcified hematoma, cold abscess or soft tissue tumor [7] [8].

Biological diagnosis is mainly based on serological ELISA and indirect hamoaglutination which are positive in $90 \%$. In fact, $<30 \%$ of serologies were positive in a cohort of patients with musculoskeletal echinococcosis of echinococcosis of liver while for musculoskeletal hydatosis they were positive in only $26 \%$ $28 \%$ of case [7]. Pericystectomy constitutes the best surgical approach for the treatment of muscular HC in cases of small superficial cysts or cysts not adhering to vascular nerve [8] [9].

In our 3 case, this surgical approach was performed to extract the HC completely intact without rupture and was achieved in 2 cases while, in one case (case No. 3) The cyst was ruptured during its intramuscular dissection and in spite of that, she passed well without intra or post-operative early or late complications. Use of preoperative hypertonic $10 \%$ saline solution is mandatory to 
prevent the dissemination of protoscoleces [8] [9].

To prevent postoperative recurrence of the cyst adjuvant chemotherapy in the form of albendazole $(15 \mathrm{mg} / \mathrm{kg} /$ day $)$ in preoperative and postoperative time is recommended by many authors but some authors recommend the use of albendazole $(400 \mathrm{mg} /$ day) in peri- or postoperative treatment [8]. Others claim that medical treatment has little place in muscular HC management and that its use should be limited, possibly associated with praziquantel, to complicated cases [8] [9] [10]. For our patients, we decided to use albendazole for 10 days preoperatively and for 3 months postoperatively.

Starting medical treatment by albenazole before surgery reduce intra-cystic pressure, soften cysts of hydatic, facilitating their drainage and aspiration during surgery, while it was stopped parasitic dissemination and recurrence of disease,when it used after surgery.

\section{Summary}

Hydatid cyst of musculoskeletal is a very rare disease even in endemic areas. The cysts are usually discovered accidentally by the patient because of nonspecific dull aching pain. The definitive diagnosis is confirmed by clinical, radiological CT or MRI and laboratory investigation which is mainly ELISA test for Echinococcus granulosus Ab. Pericystectomy combined with albendazole is the standard treatment of this lesion. Finally, true diagnosis and treatment is very important to prevent severe complication of this disease, which may be a fatal disease.

\section{Conflicts of Interest}

The authors have no financial disclosures or conflicts of interest to declare.

\section{Ethical Approval}

All surgical procedure approved by IBN SINA hospital and Sana'a University of Medicine and Healthy Science ethical approval No.12984.

\section{Informed Consent}

The patient gives informed consent for publication.

\section{References}

[1] Salamone, G., Licari, L., Randisi, B., Di Carlo, P., Tutino, R., Falco, N., Augello, G., Raspanti, C., Cocorullo, G. and Gulotta, G. (2016) A Primary Subcutaneous Hydatid Cyst in the Thigh. A Case Report. Annali Italiani di Chirurgia, 87, 1-5.

[2] Abumunaser, L. (2018) Primary Intermuscular Hydatid Cyst of the Posterior Thigh: A Rare Presentation. The Egyptian Orthopaedic Journal, 52, 333-335. https://doi.org/10.4103/eoj.eoj_80_17

[3] Hamdi, M.F., Touati, B. and Abid, A. (2010) Primary Hydatid Cyst of the Biceps Femoris. Musculoskeletal Surgery, 94, 59-61. https://doi.org/10.1007/s12306-010-0056-9 
[4] Agha, R.A., Borrelli, M.R., Farwana, R., Koshy, K., Fowler, A.J., Orgill, D.P., Zhu, H., Alsawadi, A., Noureldin, A., Rao, A., Enam, A., Thoma, A., Bashashati, M., Vasudevan, B., Beamish, A., Challacombe, B., De Wilde, R.L., Machado-Aranda, D., Laskin, D., Muzumdar, D., D’cruz, A., Manning, T., Healy, D., Pagano, D., Goel, P., Ranganathan, P., Pai, P.S., Raja, S., Ather, M.H., Kadioäžlu, H., Nixon, I., Mukherjee, I., Gómez Rivas, J., Raveendran, K., Derbyshire, L., Valmasoni, M., Chalkoo, M., Raison, N., Muensterer, O., Bradley, P., Roberto, C., Afifi, R., Rosin, D., Klappenbach, R., Wynn, R., Giordano, S., Basu, S., Surani, S., Suman, P., Thorat, M. and Kasi, V. (2018) The SCARE 2018 Statement: Updating Consensus Surgical CAse REport (SCARE) Guidelines. International Journal of Surgery, 60, 132-136. https://doi.org/10.1016/j.ijsu.2018.10.028

[5] Sousa, R., Lozano, R., Torcal, J., Tejero, E., Navarro, A., García-Alvarez, F., García-Alvarez, I., Navarro-Zorraquino, M., Salinas, J.C., Torcal, J., Salinas, J.C., Navarro, A., García-Alvarez, I., Navarro-Zorraquino, M., Sousa, R., Tejero, E. and Lozano, R. (2002) Musculoskeletal Hydatid Disease: A Report of 13 Cases. Acta Orthopaedica Scandinavica, 73, 227-231. https://doi.org/10.1080/000164702753671858

[6] Tatari, H., Baran, Ö., Sanlıdağ, T., Göre, O., Ak, D., Manisalı, M. and Havıtçığlu, H. (2001) Primary Intramuscular Hydatidosis of Supraspinatus Muscle. Archives of Orthopaedic and Trauma Surgery, 121, 93-94. https://doi.org/10.1007/PL00013775

[7] Gougoulias, N.E., Varitimidis, S.E., Bargiotas, K.A., Dovas, T.N., Karydakis, G. and Dailiana, Z.H. (2010) Skeletal Muscle Hydatid Cysts Presenting as Soft Tissue Masses. Hippokratia, 14, 126-130.

[8] Jerbi Omezzine, S., Abid, F., Mnif, H., Hafsa, C., Thabet, I., Abderrazek, A., Sassi, N. and Hamza, H.A. (2010) Primary Hydatid Disease of the Thigh. A Rare Location. Orthopaedics \& Traumatology: Surgery \& Research, 96, 90-93.

https://doi.org/10.1016/j.otsr.2009.10.016

[9] Madhar, M., Aitsoultana, A., Chafik, R., Elhaoury, H., Saidi, H. and Fikry, T. (2013) Primary Hydatid Cyst of the Thigh: On Seven Cases. Musculoskeletal Surgery, 97, 77-79. https://doi.org/10.1007/s12306-011-0157-0

[10] Mseddi, M., Mtaoumi, M., Dahmene, J., Ben Hamida, R., Siala, A., Moula, T. and Ben Ayeche, M.L. (2005) Hydatid Cysts in Muscles: Eleven Cases. Revue de Chirurgie Orthopédique et Réparatrice de I Appareil Moteur, 91, 267-271. http://ovidsp.ovid.com/ovidweb.cgi?T=JS\&PAGE=reference\&D=emed7\&NEWS=N \&AN=2005219601 https://doi.org/10.1016/S0035-1040(05)84313-2 